\title{
Impact of surface Albedo on Martian photochemistry
}

\author{
Deepak Singh* \\ Physical Research Laboratory, Ahmedabad, India
}

\author{
Key Points: \\ - Newly simulated surface albedo affects the concentration of gaseous species in the Martian atmosphere \\ - Updated model causes significant changes in the concentration of Martian gaseous species \\ - Photochemically neutral species remain unaffected by the albedo changes
}

Citation: Singh, D. (2020). Impact of surface Albedo on Martian photochemistry. Earth Planet. Phys., 4(3), $206-211$. http://doi.org/10.26464/epp2020025

\begin{abstract}
Solar energy is the primary driving force behind a planet's climate system, and surface albedo plays a key role in determining the energy budget of the planet. Coupling the Snow, Ice, and Aerosol Radiation (SNICAR) with the Laboratoire de Météorologie Dynamique (LMD) Mars General Circulation Model (MGCM) to create a new coupled model leads to an approximately $4 \%$ drop in the net $\mathrm{CO}_{2}$ ice deposition on Mars. Newly simulated surface albedo affects the concentration of gaseous species in the Martian atmosphere (condensation-sublimation cycle). The new set-up also impacts the solar energy available in the atmosphere. These two effects together lead to subsequent and significant changes in other chemical species in the Martian atmosphere. Compared with results of the MGCM model alone, in the new coupled model $\mathrm{CO}_{2}$ (gas) and $\mathrm{O}_{3}$ show a drop of about $1.17 \%$ and $8.59 \%$ in their respective concentrations, while $\mathrm{H}_{2} \mathrm{O}$ (vapor) and $\mathrm{CO}$ show an increase of about $13.63 \%$ and $0.56 \%$ in their respective concentrations. Among trace species, $\mathrm{OH}$ shows a maximum increase of about $29.44 \%$, while the maximum drop of $11.5 \%$ is observed in the O concentration. Photochemically neutral species such as $\mathrm{Ar}$ and $\mathrm{N}_{2}$ remain unaffected by the albedo changes.
\end{abstract}

Keywords: Mars; Albedo; snow; photochemistry; climate modelling

\section{Introduction}

Reactions that are initiated by the absorption of a photon of light by a chemical species are known as photochemical reactions. $\mathrm{CO}_{2}$ is the major component in the Martian atmosphere, with a mixing ratio of 95\% (Franz et al., 2017), derived using the most recent data from the Curiosity Mars rover. The primary driver of the photochemistry of the Mars atmosphere is the photo-dissociation of its dominant gas, $\mathrm{CO}_{2}$, which is continuously photolyzed producing $\mathrm{CO}$ and $\mathrm{O}$, and subsequently $\mathrm{O}_{2}$. Other atmospheric components (such as $\mathrm{O}_{3}, \mathrm{H}_{2} \mathrm{O}, \mathrm{CO}$, and dust) also play important roles in the photochemistry and ion chemistry of the Mars atmosphere.

$\mathrm{CO}$ is produced mainly by the photolysis of $\mathrm{CO}_{2}$ but, due to its long lifetime ( 3.17 Earth years) (González-Galindo et al., 2005), $\mathrm{CO}$ acts like a dynamical tracer. The seasonal variation of $\mathrm{CO}$ is connected primarily with the condensation of $\mathrm{CO}_{2}$ and the dynamical transport (Krasnopolsky, 2015). CO was detected for the first time from high-resolution Fourier transform spectra by Kaplan et al. (1969) and the mixing ratio retrieved was $800 \pm 300$ ppm. Retrievals from recent spacecraft measurements, such as CRISM onboard MRO, PFS onboard MEX, and OMEGA onboard MEX, show an approximate CO mixing ratio of $700 \mathrm{ppm}$ in the

Correspondence to: D. Singh, sdeepak@umich.edu

Received 21 OCT 2019; Accepted 28 JAN 2020.

Accepted article online 05 MAR 2020.

(C) 2020 by Earth and Planetary Physics.
Martian atmosphere (Franz et al., 2015, 2017). The opposite reaction, i.e., $\mathrm{CO}+\mathrm{O}+\mathrm{M} \rightarrow \mathrm{CO}_{2}+\mathrm{M}$ is very slow and is rotationally forbidden (Atreya and Gu ZG, 1995). McElroy and Donahue (1972) first argued that $\mathrm{CO}$ is re-oxidized by $\mathrm{OH}$, suggesting the presence of $\mathrm{OH}$ molecules produced by photolysis of water vapor in Mars's atmosphere. Such a low abundance of CO shows the stability of the Martian atmosphere.

Water vapor, the only source of the catalytic species $\mathrm{HO}_{\mathrm{x}}$ in the Martian atmosphere, is one of the atmosphere's most variable trace species and is also responsible for the atmosphere's stability. The seasonal cycle of water vapor is driven by condensation and sublimation of the polar frost (Barker et al., 1970). The first detailed knowledge of Martian water vapor was obtained from the Mars Atmospheric Water Detector (MAWD) instrument onboard the Viking orbiter (Farmer et al., 1977; Jakosky and Farmer, 1982). Global and seasonal variation of water vapor shows a net transport of water vapor from the southern polar region to the northern polar region during a Martian year (Farmer and Doms, 1979). This extra water vapor corresponds to $1-2 \mathrm{mg} / \mathrm{cm}^{2}$ of the deposited ice on the surface. Thermal Emission Spectrometer (TES) observations predicted a lower water vapor gradient from south to north as compared to MAWD retrievals (Smith, 2002, 2004; Pankine et al., 2010).

Also playing an important role in the photochemistry and stability of the Martian atmosphere is ozone. The ultraviolet (UV) spec- 
trometer onboard the Mariner 7 flyby detected ozone for the firsttime using absorptions of the Hartley band (centered at $255 \mathrm{~nm}$ ) (Barth and Hord, 1971; Modak et al., 2019). Global distribution of Martian ozone was reported from remote sensing observations by Perrier et al. (2006) and Clancy et al. (2016). Ozone was underestimated in early modeling studies (Nair et al., 1994). However, Lefèvre et al. (2004) achieved better agreement with observations after establishing, and incorporating, a complete water cycle. Various past studies have shown that ozone is anti-correlated with the abundance of water vapor (Barth et al., 1973; Lefèvre et al., 2004; Fedorova et al., 2006; Fast et al., 2006; Clancy et al., 2016; Willame et al., 2017; Modak et al., 2019). Water vapor is abundant on the northern polar cap as compared to the southern polar cap. $\mathrm{O}_{3}$ is produced primarily by the dissociation of $\mathrm{CO}_{2}$ and $\mathrm{O}_{2}$ (which produces the $\mathrm{O}$ atom) and combination with $\mathrm{O}_{2}$ to produce $\mathrm{O}_{3}$. The photo-dissociation occurs only in the sunlit areas, and $\mathrm{O}_{3}$ is transported over dark regions. The degree of anti-correlation between $\mathrm{O}_{3}$ and water vapor varies from region to region (Lefèvre et al., 2004). In general, at all locations $\mathrm{O}_{3}$ is at its maximum during winter and minimum during summer, due to its anti-correlation with water vapor (Barth et al., 1973).

Table 1 lists the atmospheric mixing ratios of some selected major species in the Martian atmosphere (Mumma et al., 2009; Encrenaz et al., 2011; Franz et al., 2015, 2017; McConnochie et al., 2018). The concentration of trace gases such as $\mathrm{H}_{2} \mathrm{O}$ and $\mathrm{O}_{3}$ has high variability due to seasonal dependence. Table 2 lists four seasons on Mars for both hemispheres with solar longitude (Ls) ranges (Cantor et al., 2001).

Surface albedo controls the amount of solar energy reflected or absorbed by a planet's surface and has a significant impact on any planet's energy budget. Since solar energy is the key to initiate (and continue) photochemical reactions, any change in solar energy flux will have a direct impact on atmospheric photochem-

Table 1. Atmospheric concentration of selected species in the Martian atmosphere.

\begin{tabular}{cc}
\hline Chemical specie & Atmospheric concentration \\
\hline $\mathrm{CO}_{2}$ & $94.9 \%$ \\
$\mathrm{~N}_{2}$ & $2.79 \%$ \\
$\mathrm{Ar}$ & $2.08 \%$ \\
$\mathrm{O}_{2}$ & $0.174 \%$ \\
$\mathrm{CO}$ & $747 \mathrm{ppm}$ \\
$\mathrm{H}_{2} \mathrm{O}$ & $0-200 \mathrm{ppm}$ (column averaged) \\
$\mathrm{O}_{3}$ & $0.02-0.2 \mathrm{ppm}$ \\
\hline
\end{tabular}

Table 2. Distribution of seasons on Mars with solar longitude (Ls) span.

\begin{tabular}{ccc}
\hline Ls range (degrees) & Northern Hemisphere & Southern Hemisphere \\
\hline $0^{\circ}-90^{\circ}$ & Spring & Fall/Autumn \\
$90^{\circ}-180^{\circ}$ & Summer & Winter \\
$180^{\circ}-270^{\circ}$ & Fall/Autumn & Spring \\
$270^{\circ}-360^{\circ}$ & Winter & Summer \\
\hline
\end{tabular}

istry. In this work, I have quantified the impact of surface albedo on the mass budget of various photochemical species in the Martian atmosphere by coupling the Laboratoire de Météorologie Dynamique (LMD) Mars General Circulation Model (hereafter MGCM) to the extended Snow, Ice, and Aerosol Radiation (SNICAR) model (Flanner et al., 2007, 2009; Singh and Flanner, 2016). I assess global and seasonal changes in the mass budget of various photochemical species using a mean solar insolation scenario. This work is focused on understanding the change in the mass budget due to albedo changes, so initial solar insolation would not have any impact on the calculations. All the changes reported in this paper are with respect to the uncoupled MGCM unless stated otherwise.

\section{Model Description \& Methodology}

The MGCM is a 3-D General Circulation Model that simulates the temporal evolution of the different physical processes that control or describe the meteorology and climate that covers the entire Martian atmosphere. Along with various schemes such as the $\mathrm{CO}_{2}$ (Forget et al., 1998; 1999), water (Navarro et al., 2014), and dust (Madeleine et al., 2011) cycles, the MGCM (Pottier et al., 2017; Singh et al., 2018) also includes a state-of-the-art gas-phase photochemical module (Lefèvre et al., 2004) to provide a realistic description of the concentrations and variations of various species in the Martian atmosphere.

SNICAR utilizes the multiple scattering, multi-layer two-stream radiative approximation described by Toon et al. (1989), with the delta-hemispheric mean approximation. The current version of SNICAR utilizes 480 bands spanning $0.2-5.0 \mu \mathrm{m}$ at $10 \mathrm{~nm}$ spectral resolution to produce a directional-hemispherical albedo (Singh and Flanner, 2016). Singh et al. (2018) prognostically determine snow (both $\mathrm{H}_{2} \mathrm{O}$ and $\mathrm{CO}_{2}$ ) albedos interactively within the MGCM (integrated with MGCM) using the framework of Singh and Flanner (2016).

First, I determine the total mixing concentration of each species using the MGCM. Next, I convert these concentrations into the total mass of each particular species using its molar mass. After that, I couple SNICAR with MGCM (S-MGCM) using the framework of Singh et al. (2018) to determine new concentrations, and total mass. Finally, I determine the change in the respective chemical species by subtracting S-MGCM values from MGCM values.

\section{Results and Discussion}

Singh et al. (2018) showed changes in $\mathrm{CO}_{2}$ ice deposition, surface pressure, and temperature after the integration of SNICAR with MGCM. Due to a higher simulated surface albedo with SNICAR, the net $\mathrm{CO}_{2}$ ice deposition decreases by about 4\% (Singh et al., 2018). This leads to subsequent changes in other chemical species due to various photochemical interactions within the atmosphere. Figure 1 shows the change in the broadband surface albedo (Band-averaged values are weighted with solar spectral irradiance measurements from Labs and Neckel (1968)) due to the integration of SNICAR with MGCM. The most significant change in albedo is observed in the southern hemisphere from $L s=100^{\circ}$ to $\mathrm{Ls}=200^{\circ}$. A global map (Figure 2) showing changes in surface temperature indicates maximum impact during the southern 


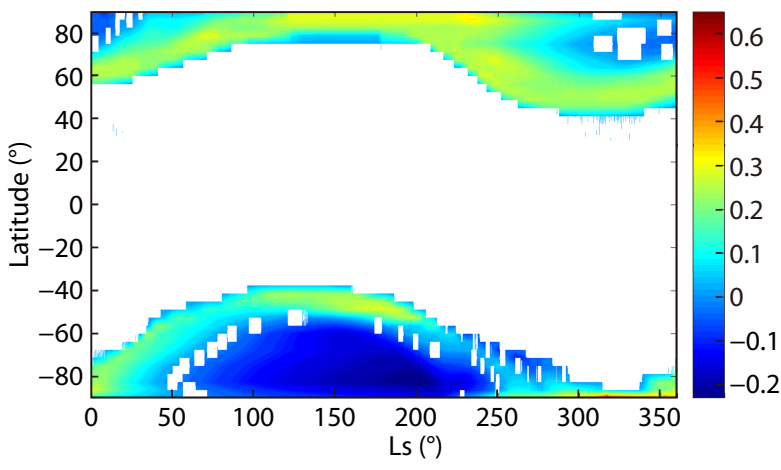

Figure 1. Global map (longitudinally averaged) of albedo change determined by subtracting S-MGCM albedo values from MGCM albedo values.

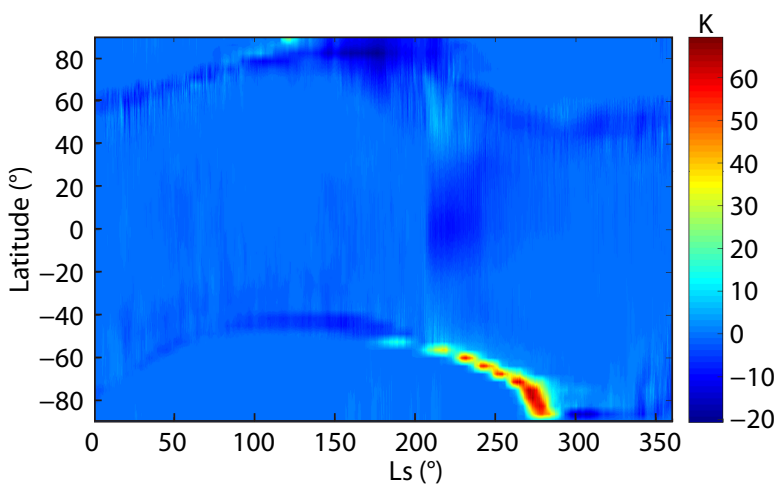

Figure 2. Global map (longitudinally averaged) of surface temperature change determined by subtracting S-MGCM surface temperature from MGCM temperature.

spring and summer seasons ( $\mathrm{Ls}=200^{\circ}$ to $\mathrm{Ls}=300^{\circ}$ ). The change in surface albedo causes a reduction in surface temperature values (global average) of about $1.7 \mathrm{~K}(0.87 \%)$ (Singh et al., 2018). Surface temperature plays a significant role in determining reaction coefficients. However, due to a very small change in surface temperature, the reaction coefficients are not significantly affected in our analysis.

Table 3 lists changes in concentrations of various chemical species due to the effect of revised albedo. The positive sign indicates the decrement in the concentration of respective species, and the negative sign indicates the increment of concentration of respective species with respect to MGCM. The changes in major species $\left(\mathrm{CO}_{2}, \mathrm{CO} \& \mathrm{O}_{2}\right)$ are relatively small, while the trace gases $\left(\mathrm{H}_{2} \mathrm{O} \& \mathrm{O}_{3}\right)$ show more significant changes. This happens because a small change in dynamics would significantly impact the concentration of minor species. Inert gases like $\mathrm{N}_{2}$ and $\mathrm{Ar}$ do not show any significant change in their concentrations due to their very little or no participation in Martian photochemistry.

Among major atmospheric constituents, carbon dioxide and ozone show a drop in their concentrations while water vapor, carbon monoxide, and oxygen show an increase in their respective concentrations. Water vapor shows the maximum change in the total mass of the species, followed by ozone and carbon dioxide. The photolysis of water vapor provides odd hydrogen radicals
Table 3. Net change in total global average mass of chemical species in the Martian atmosphere. Positive change indicates the fall, and negative change indicates the rise in respective species with respect to MGCM.

\begin{tabular}{cc}
\hline Chemical Species & Change (\%) \\
\hline $\mathrm{CO}_{2}$ (gas) & 1.17 \\
$\mathrm{H}_{2} \mathrm{O}$ (vapor) & -13.63 \\
$\mathrm{O}_{3}$ & 8.59 \\
$\mathrm{CO}$ & -0.56 \\
$\mathrm{O}_{2}$ & -0.23 \\
$\mathrm{O}$ & 11.5 \\
$\left.\mathrm{O}^{1} \mathrm{D}\right)$ & 0.78 \\
$\mathrm{H}_{2}$ & -1.48 \\
$\mathrm{H}$ & -12.97 \\
$\mathrm{OH}$ & -29.44 \\
$\mathrm{HO}_{2}$ & 6.14 \\
$\mathrm{H}_{2} \mathrm{O}_{2}$ & -4.77 \\
$\mathrm{Ar}$ & 0 \\
$\mathrm{~N}_{2}$ & 0 \\
\hline
\end{tabular}

$\left(\mathrm{HO}_{\mathrm{x}}\right)$ which are responsible for the catalytic loss of $\mathrm{O}_{3}$ (Nair et al., 1994). As ozone is anti-correlated with the abundance of water vapor, therefore increase in water vapor content decreases the ozone content with the change in albedo. $\mathrm{O}_{3}$ is also important in determining the habitability of Mars, as it modulates the surface UV flux.

Figure 3 shows the annual variation of global average concentrations of four major species $\left(\mathrm{CO}_{2}, \mathrm{CO}, \mathrm{O}_{3} \& \mathrm{H}_{2} \mathrm{O}\right.$ (vapor)) in the Martian atmosphere. $\mathrm{CO}_{2}$ and $\mathrm{O}_{3}$ observe a drop in concentration during the southern spring season, while $\mathrm{CO}$ and $\mathrm{H}_{2} \mathrm{O}$ (vapor) show an increase in concentration mostly during northern summer. The amount of $\mathrm{CO}$ and $\mathrm{H}_{2} \mathrm{O}$ (vapor) increases during late southern winter and extends up to early southern spring, which coincides with albedo change in S-MGCM simulations around the same time (Figure 1). Drop in the amounts of $\mathrm{CO}_{2}$ and $\mathrm{O}_{3}$ observe a slight delay starting around early southern spring and extending up to mid-spring. The delay is caused primarily by the time taken by species to move around and react with other species.

Figure 4 shows the annual variation of longitudinal-averaged concentrations of four major species in the Mars atmosphere. Surface albedo is a strong positive feedback mechanism (e.g., Bony et al., 2006; Winton, 2006; Randall et al., 2007; Soden et al., 2008; Shell et al., 2008; Flato et al., 2013; Singh et al., 2015) that controls the amount of solar energy available to be utilized by the planetary surface and atmosphere. As albedo increases, the surface reflects more solar energy back into space. With lower energy available, both surface and atmosphere become colder and trap more gases via condensation. $\mathrm{CO}_{2}$, being the most dominant species, shows signs of changes in its respective concentration over almost the entire globe during the southern spring season. $\mathrm{CO}$ is produced primarily by the photolysis of $\mathrm{CO}_{2}$ from solar energy. Therefore, 

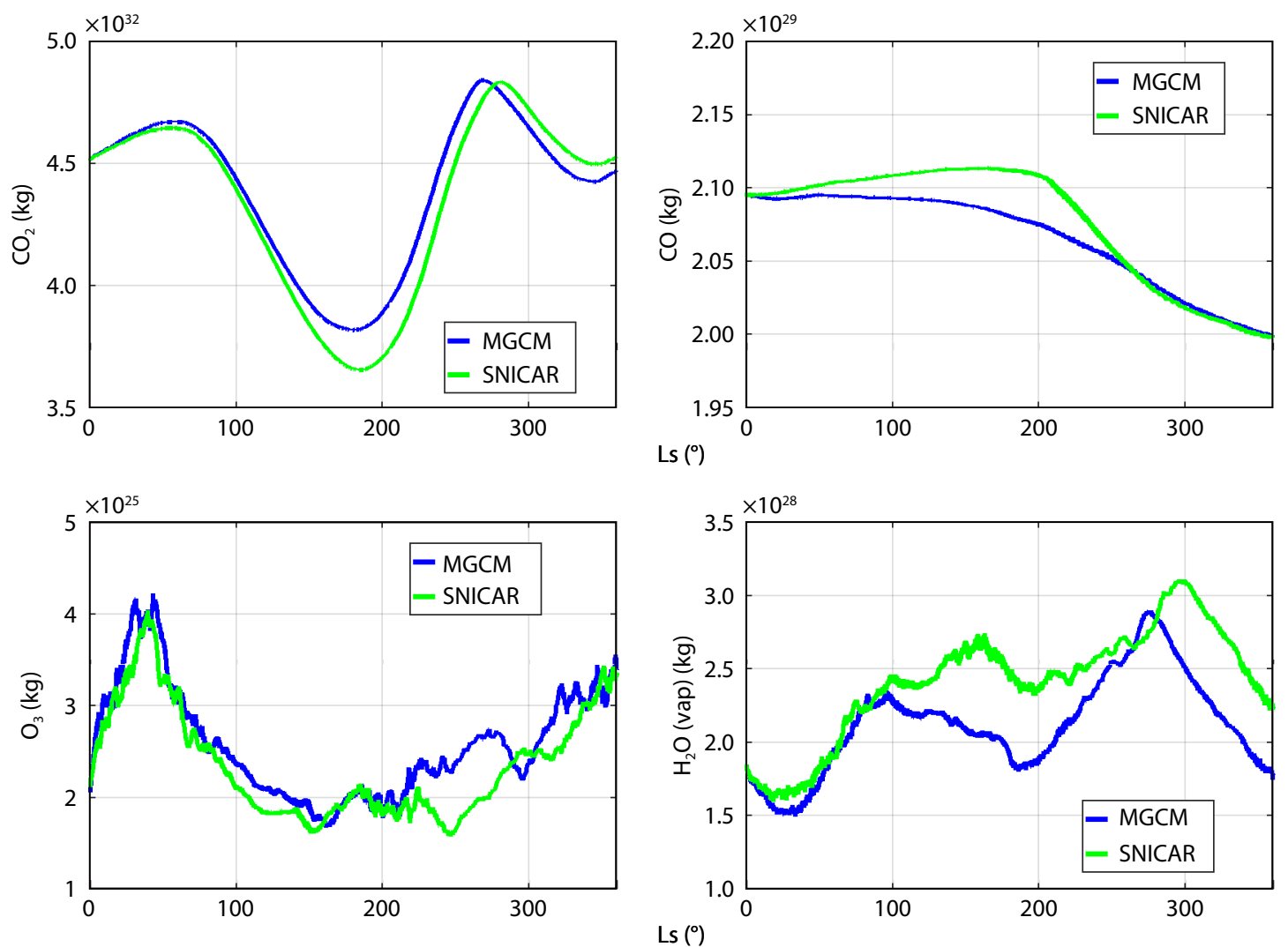

Figure 3. Global average plots of concentration of major species for one Martian year. Blue line indicates values determined using MGCM simulations, and green line indicates values determined using S- MGCM simulations.
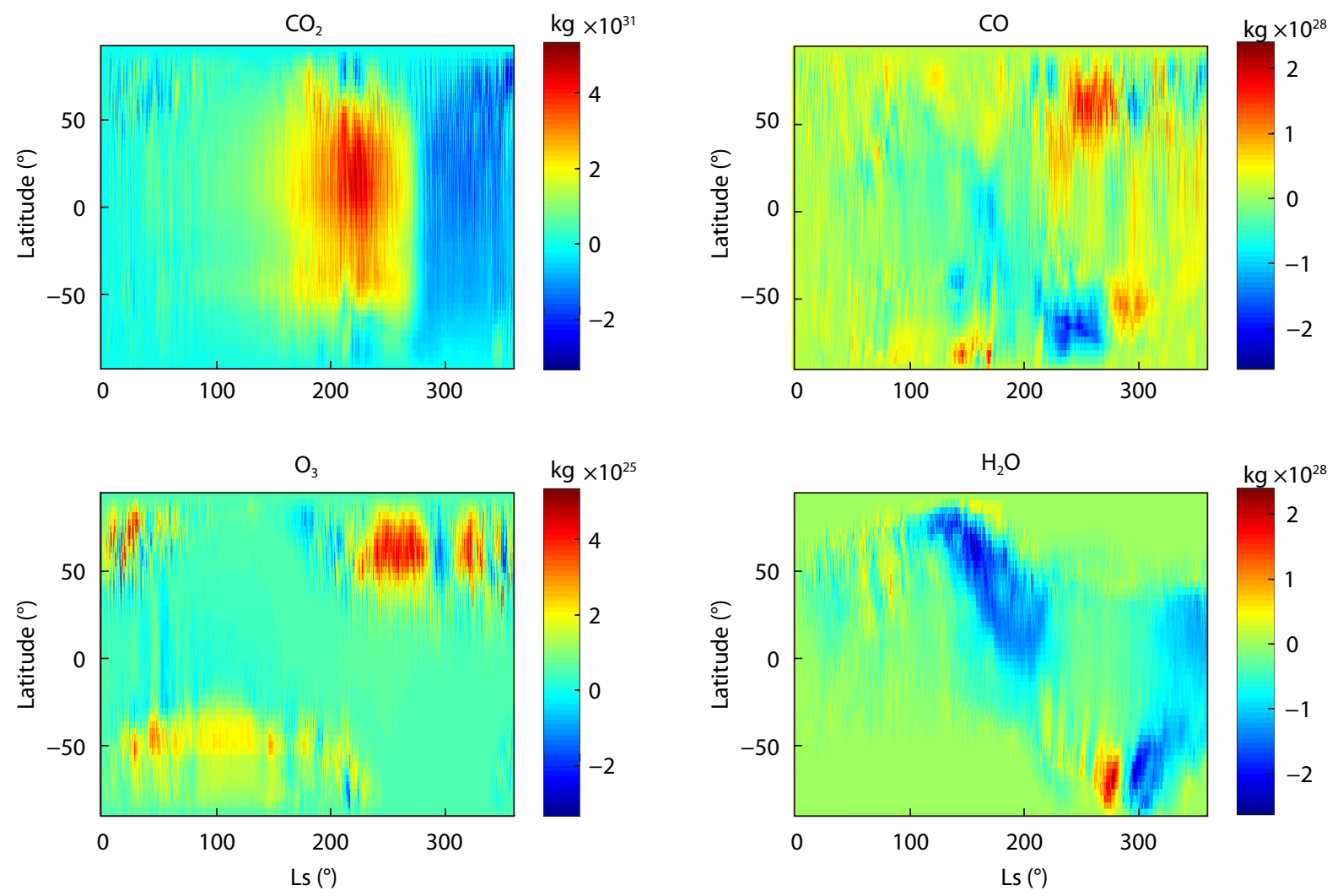

Figure 4. Longitudinally-averaged global maps (difference in concentrations) of four major atmospheric species in the Martian atmosphere. The difference is determined by subtracting S-MGCM albedo from MGCM albedo values. 
CO shows contrasting changes in both hemispheres near late summer (Northern Hemisphere) / early spring (Southern Hemisphere), which is mostly consistent with albedo changes observed in S-MGCM.

Since water vapor and ozone are anti-correlated (Lefèvre et al., 2004; Fedorova et al., 2006; Fast et al., 2006; Clancy et al., 2016; Willame et al., 2017; Modak et al., 2019), we observe opposite changes for both species for the most part during the entire year. Ozone is more abundant in colder regions; water is more abundant in warmer regions (Lefèvre et al., 2004, Fig.1). The latitudinal anomalies are caused primarily by a relative abundance of certain species at a certain latitude. Therefore, the changes are more pronounced when the abundance is relatively high.

\section{Conclusions}

Surface albedo plays a significant role in managing a planet's energy budget. The simulated albedo in the new S-MGCM has an impact on the amount of solar energy available in the atmosphere for various gaseous species. The change in surface temperature is too small to cause any significant change in the chemical reaction rates. However, the revised surface albedo changes the concentration of certain atmospheric species by changing the condensation-sublimation cycle. In this case, changes in albedo directly change the amount of $\mathrm{CO}_{2}$ available in the atmosphere, due to the lower condensation of $\mathrm{CO}_{2}$ gas into $\mathrm{CO}_{2}$ ice. Changes in both the sublimation-condensation cycle and in solar energy impact chemical reactions, which further impact the other photochemical reactions occurring in the atmosphere, depending on the availability of other species, and environmental conditions in the vicinity.

Except for Argon and Nitrogen, the new simulated albedo has impacted all other species (either a drop or increase in their net concentrations). Among major species, water vapor observes the maximum change followed by ozone, carbon dioxide, and carbon monoxide. The concentrations of water vapor and ozone are highly affected by seasonal changes on Mars, therefore they react most to the albedo changes caused by the integration of SNICAR into the MGCM. Trace species generally show higher changes as compared to major species, due to their higher dependency on seasons.

\section{Acknowledgments}

The web version of Mars Climate Database v5.3 created using the MGCM can be interactively accessed on the web at: http://wwwmars.Imd.jussieu.fr/mars/access.html. A single-layer implementation of SNICAR can be operated interactively on the web at: http://snow.engin.umich.edu. This work was partially supported by DST-INSPIRE Faculty Award.

\section{References}

Atreya, S. K., and Gu, Z. G. (1995). Photochemistry and stability of the atmosphere of Mars. Adv. Space Res., 16(6), 57-68. https://doi.org/10.1016/0273-1177(95)00250-I

Barker, E. S., Schorn, R. A., Woszczyk, A., Tull, R. G., and Little, S. J. (1970). Mars: Detection of atmospheric water vapor during the southern hemisphere spring and summer season. Science, 170(3964), 1308-1310. https://doi.org/10.1126/science.170.3964.1308

Barth, C. A., and Hord, C. W. (1971). Mariner ultraviolet spectrometer: Topography and polar cap. Science, 173(3993), 197-201. https://doi.org/10.1126/science.173.3993.197

Barth, C. A., Hord, C. W., Stewart, A. I., Lane, A. L., Dick, M. L., and Anderson, G. P. (1973). Mariner 9 ultraviolet spectrometer experiment: Seasonal variation of ozone on Mars. Science, 179(4075), 795-796. https://doi.org/10.1126/science.179.4075.795

Bony, S., Colman, R., R., Kattsov, V. M., Allan, R. P., Bretherton, C. S., Dufresne, J. L., Hall, A., Hallegatte, S., Holland, M. M., ... Webb, M. J. (2006). How well do we understand and evaluate climate change feedback processes?. J. Climate, 19(15), 3445-3482. https://doi.org/10.1175/JCLI3819.1

Cantor, B. A., James, P. B., Caplinger, M., and Wolff, M. J. (2001). Martian dust storms: 1999 Mars orbiter camera observations. J. Geophys. Res.: Planets, 106(E10), 23653-23687. https://doi.org/10.1029/2000JE001310

Clancy, R. T., Wolff, M. J., Lefèvre, F., Cantor, B. A., Malin, M. C., and Smith, M. D. (2016). Daily global mapping of Mars ozone column abundances with MARCI UV band imaging. Icarus, 266, 112-133. https://doi.org/10.1016/j.icarus.2015.11.016

Encrenaz, T., Greathouse, T. K., Richter, M. J., Lacy, J. H., Fouchet, T., Bézard, B., Lefèvre, F., Forget, F., and Atreya, S. K. (2011). A stringent upper limit to $\mathrm{SO}_{2}$ in the Martian atmosphere. Astron. Astrophys., 530, A37. https://doi.org/10.1051/0004-6361/201116820

Farmer, C. B., Davies, D. W., Holland, A. L., LaPorte, D. D., and Doms, P. E. (1977). Mars: Water vapor observations from the Viking orbiters. J. Geophys. Res., 82(28), 4225-4248. https://doi.org/10.1029/JS082i028p04225

Farmer, C. B., and Doms, P. E. (1979). Global seasonal variation of water vapor on Mars and the implications for permafrost. J. Geophys. Res.: Solid Earth, 84(B6), 2881-2888. https://doi.org/10.1029/JB084iB06p02881

Fast, K., Kostiuk, T., Espenak, F., Annen, J., Buhl, D., Hewagama, T., A'Hearn, M. F., Zipoy, D., Livengood, T. A., ... Schmülling, F. (2006). Ozone abundance on Mars from infrared heterodyne spectra: I. Acquisition, retrieval, and anticorrelation with water vapor. Icarus, 181(2), 419-431. https://doi.org/10.1016/j.icarus.2005.12.001

Fedorova, A., Korablev, O., Bertaux, J. L., Rodin, A., Kiselev, A., and Perrier, S. (2006). Mars water vapor abundance from SPICAM IR spectrometer: Seasonal and geographic distributions. J. Geophys. Res.: Planets, 111(E9), E09S08. https://doi.org/10.1029/2006JE002695

Flanner, M. G., Zender, C. S., Randerson, J. T., and Rasch, P. J. (2007). Present-day climate forcing and response from black carbon in snow. J. Geophys. Res. Atmos, 112(D11), D11202. https://doi.org/10.1029/2006JD008003

Flanner, M. G., Zender, C. S., Hess, P. G., Mahowald, N. M., Painter, T. H., Ramanathan, V., and Rasch, P. J. (2009). Springtime warming and reduced snow cover from carbonaceous particles. Atmos. Chem. Phys., 9(7), 2481-2497. https://doi.org/10.5194/acp-9-2481-2009

Flato, G., Marotzke, J., Abiodun, B., Braconnot, P., Chou, S. C., Collins, W., Cox, P., Driouech, F., Emori, S., ... Rummukainen, M. (2013). Evaluation of climate models. In Climate Change 2013: The Physical Science Basis. Contribution of Working Group I to the Fifth Assessment Report of the Intergovernmental Panel on Climate Change (pp. 741-866). Cambridge, United Kingdom and New York, NY, USA: Cambridge University Press.

Forget, F., Hourdin, F., and Talagrand, O. (1998). $\mathrm{CO}_{2}$ snowfall on Mars: Simulation with a general circulation model. Icarus, 131(2), 302-316. https://doi.org/10.1006/icar.1997.5874

Forget, F., Hourdin, F., Fournier, R., Hourdin, C., Talagrand, O., Collins, M., Lewis, S. R., Read, P. L., and Huot, J. P. (1999). Improved general circulation models of the Martian atmosphere from the surface to above $80 \mathrm{~km}$. J. Geophys. Res.: Planets, 104(E10), 24155-24176. https://doi.org/10.1029/1999JE001025

Franz, H. B., Trainer, M. G., Wong, M. H., Mahaffy, P. R., Atreya, S. K., Manning, H. L. K., and Stern, J. C. (2015). Reevaluated Martian atmospheric mixing ratios from the mass spectrometer on the Curiosity rover. Planet. Space Sci., 109110, 154-158. https://doi.org/10.1016/j.pss.2015.02.014

Franz, H. B., Trainer, M. G., Malespin, C. A., Mahaffy, P. R., Atreya, S. K., Becker, R. H., Benna, M., Conrad, P. G., Eigenbrode, J. L., ... Wong, M. H. (2017). Initial SAM calibration gas experiments on Mars: Quadrupole mass spectrometer 
results and implications. Planet. Space Sci., 138, 44-54.

https://doi.org/10.1016/j.pss.2017.01.014

González-Galindo, F., López-Valverde, M. A., Angelats i Coll, M., and Forget, F. (2005). Extension of a Martian general circulation model to thermospheric altitudes: UV heating and photochemical models. J. Geophys. Res.: Planets, 110(E9), E09008. https://doi.org/10.1029/2004JE002312

Jakosky, B. M., and Farmer, C. B. (1982). The seasonal and global behavior of water vapor in the Mars atmosphere: Complete global results of the Viking atmospheric water detector experiment. J. Geophys. Res.: Solid Earth, 87(B4), 2999-3019. https://doi.org/10.1029/JB087iB04p02999

Kaplan, L. D., Connes, J., and Connes, P. (1969). Carbon monoxide in the Martian atmosphere. Astrophys. J., 157, L187. https://doi.org/10.1086/180416

Krasnopolsky, V. A. (2015). Variations of carbon monoxide in the Martian lower atmosphere. Icarus, 253, 149-155. https://doi.org/10.1016/j.icarus.2015.03.006

Labs, D., Neckel, H. (1968). The radiation of the solar photosphere from $2000 \AA$ to $100 \mu \mathrm{m}$. Zeitschrift fur Astrophysik, 69, 1.

Lefèvre, F., Lebonnois, S., Montmessin, F., and Forget, F. (2004). Threedimensional modeling of ozone on Mars. J. Geophys. Res.: Planets, 109(E7), E07004. https://doi.org/10.1029/2004JE002268

Madeleine, J. B., Forget, F., Millour, E., Montabone, L., and Wolff, M. J. (2011). Revisiting the radiative impact of dust on Mars using the LMD Global Climate Model. J. Geophys. Res.: Planets, 116(E11), E11010. https://doi.org/10.1029/2011JE003855

McConnochie, T. H., Smith, M. D., Wolff, M. J., Bender, S., Lemmon, M., Wiens, R. C., Maurice, S., Gasnault, O., Lasue, J., ... Bell III, J. F. (2018). Retrieval of water vapor column abundance and aerosol properties from ChemCam passive sky spectroscopy. Icarus, 307, 294-326. https://doi.org/10.1016/j.icarus.2017.10.043

McElroy, M. B., and Donahue, T. M. (1972). Stability of the Martian atmosphere. Science, 177(4053), 986-988. https://doi.org/10.1126/science.177.4053.986

Modak, A., Sheel, V., and Montmessin, F. (2019). Retrieval of Martian ozone and dust from SPICAM spectrometer for MY27-MY28. J. Earth Syst. Sci., 128(6), 144. https://doi.org/10.1007/s12040-019-1167-9

Mumma, M. J., Villanueva, G. L., Novak, R. E., Hewagama, T., Bonev, B. P., DiSanti, M. A., Mandell, A. M. and Smith, M. D. (2009). Strong release of methane on Mars in northern summer 2003. Science, 323(5917), 1041-1045. https://doi.org/10.1126/science.1165243

Nair, H., Allen, M., Anbar, A. D., Yung, Y. L., and Clancy, R. T. (1994). A photochemical model of the Martian atmosphere. Icarus, 111(1), 124-150. https://doi.org/10.1006/icar.1994.1137

Navarro, T., Madeleine, J. B., Forget, F., Spiga, A., Millour, E., Montmessin, F., and Määttänen, A. (2014). Global climate modeling of the Martian water cycle with improved microphysics and radiatively active water ice clouds. J. Geophys. Res. Planets, 119(7), 1479-1495. https://doi.org/10.1002/2013JE004550

Pankine, A. A., Tamppari, L. K., and Smith, M. D. (2010). MGS TES observations of the water vapor above the seasonal and perennial ice caps during northern spring and summer. Icarus, 210(1), 58-71. https://doi.org/10.1016/j.icarus.2010.06.043

Perrier, S., Bertaux, J. L., Lefèvre, F., Lebonnois, S., Korablev, O., Fedorova, A., and Montmessin, F. (2006). Global distribution of total ozone on Mars from SPICAM/MEX UV measurements. J. Geophys. Res.: Planets, 111(E9), E09S06. https://doi.org/10.1029/2006JE002681

Pottier, A., Forget, F., Montmessin, F., Navarro, T., Spiga, A., Millour, E., Szantai, A., and Madeleine, J. B. (2017). Unraveling the Martian water cycle with high-resolution global climate simulations. Icarus, 291, 82-106. https://doi.org/10.1016/j.icarus.2017.02.016

Randall, D. A., Wood, R. A., Bony, S., Colman, R., Fichefet, T., Fyfe, J., Kattsov, V., Pitman, A., Shukla, J., ... Taylor, K. E. (2007). Climate models and their evaluation. In Climate Change 2007: The Physical Science Basis. Contribution of Working Group I to the Fourth Assessment Report of the Intergovernmental Panel on Climate Change. Cambridge, United Kingdom and New York, NY, USA: Cambridge University Press.

Shell, K. M., Kiehl, J. T., and Shields, C. A. (2008). Using the radiative kernel technique to calculate climate feedbacks in NCAR's community atmospheric model. J. Climate, 21(10), 2269-2282. https://doi.org/10.1175/2007JCLI2044.1

Singh, D., Flanner, M. G., and Perket, J. (2015). The global land shortwave cryosphere radiative effect during the MODIS era. The Cryosphere, 9(6), 2057-2070. https://doi.org/10.5194/tc-9-2057-2015

Singh, D., and Flanner, M. G. (2016). An improved carbon dioxide snow spectral albedo model: Application to Martian conditions. J. Geophys. Res.: Planets, 121(10), 2037-2054. https://doi.org/10.1002/2016JE005040

Singh, D., Flanner, M. G., and Millour, E. (2018). Improvement of Mars surface snow albedo modeling in LMD Mars GCM with SNICAR. J. Geophys. Res.: Planets, 123(3), 780-791. https://doi.org/10.1002/2017JE005368

Smith, M. D. (2002). The annual cycle of water vapor on Mars as observed by the Thermal Emission Spectrometer. J. Geophys. Res.: Planets, 107(E11), 25-1-2519. https://doi.org/10.1029/2001JE001522

Smith, M. D. (2004). Interannual variability in TES atmospheric observations of Mars during 1999-2003. Icarus, 167(1), 148-165. https://doi.org/10.1016/j.icarus.2003.09.010

Soden, B. J., Held, I. M., Colman, R., Shell, K. M., Kiehl, J. T., and Shields, C. A. (2008). Quantifying climate feedbacks using radiative kernels. J. Climate, 21(14), 3504-3520. https://doi.org/10.1175/2007JCLI2110.1

Toon, O. B., McKay, C. P., Ackerman, T. P., and Santhanam, K. (1989). Rapid calculation of radiative heating rates and photodissociation rates in inhomogeneous multiple scattering atmospheres. J. Geophys. Res., 94(D13), 16,287-16,301. https://doi.org/10.1029/JD094iD13p16287

Willame, Y., Vandaele, A. C., Depiesse, C., Lefèvre, F., Letocart, V., Gillotay, D., and Montmessin, F. (2017). Retrieving cloud, dust and ozone abundances in the Martian atmosphere using SPICAM/UV nadir spectra. Planet. Space Sci., 142, 9-25. https://doi.org/10.1016/j.pss.2017.04.011

Winton, M. (2006). Surface albedo feedback estimates for the AR4 climate models. J. Climate, 19(3), 359-365. https://doi.org/10.1175/JCLI3624.1 